\title{
How dependent is synaptic plasticity on microglial phenotype?
}

\author{
Raasay S. Jones and Marina A. Lynch \\ Trinity College Institute of Neuroscience, \\ Department of Physiology, \\ Trinity College, \\ Dublin 2. \\ Ireland.
}

\begin{abstract}
Microglia are particularly plastic cells which can be shifted from their resting state by numerous factors and adopt distinct phenotypes. The cells are multifunctional, though their main role is probably maintenance of homeostasis. Resting cells are responsible for surveillance, whereas activation induces the cells to adopt neuroprotective or neurodetrimental roles, which are anti-inflammatory or pro-inflammatory respectively. The evidence indicates that activated cells with a pro-inflammatory phenotype predominate in neurodegenerative diseases and models of neurodegeneration and that this may significantly contribute to the deteriorating neuronal function. This question is considered in this review, in particular in the context of animal models of Alzheimer's disease (AD).
\end{abstract}

\section{Highlights}

- IFN $\gamma$ and TNF $\alpha$ induce microglia to adopt a classically-activated, or M1, phenotype

- IL-4 and IL-13 induce the alternatively-activated, or M2, phenotype

- M1 activation is associated with impaired synaptic function and neurodegeneration

- $\mathrm{A} \beta$, microglial activation and impaired LTP are features in animal models of AD

- The driving force behind these changes remains to be elucidated

\section{Keywords:}

Neuroinflammation, Microglia, Astrocytes, Inflammatory cytokines, Age, Alzheimer's disease, Neuronal function. 


\section{Introduction}

The idea that microglia are 'the macrophages of the brain', although inaccurate, is useful when considering their phenotypes since there is a great deal more understanding of the biology of macrophages. However, while macrophages and microglia are cells of the myeloid lineage, microglia are derived from primitive macrophages in the yolk sac that migrate to the central nervous system (CNS) early in development (Ginhoux et al., 2010). Therefore, a fundamental difference between the cells is that they encounter entirely diverse stimuli throughout life; for example, microglia are juxtaposed with cells that are electrically active, while macrophages are exposed to a wide variety of pathogens that, in the main, do not pass the blood brain barrier and therefore are generally not encountered by microglia.

Microglia, as sentinel cells in the brain, react to any stimulus that poses a potential threat to the brain. Indeed activation of glia, especially microglia, is fundamentally responsible for the inflammatory changes that characterize the brain following exposure to any insult. For example, ischemia, injury and infection are associated with rapid microglial activation and associated inflammatory changes, but these are designed to combat the effect of the insult and ultimately return the tissue to homeostasis. This acute reaction is therefore considered to be protective. In contrast, persistent microglial activation with the associated increase in expression of inflammatory cytokines and chemokines, accompanied by recruitment of peripheral cells into the brain, characterizes chronic neuroinflammation (Lynch, 2009, 2010). It has been known for many years that neuroinflammatory changes are a characteristic of, and persist in, the brain of aged individuals and a great deal of data suggests that neuroinflammation is one of the common features of several neurodegenerative diseases (Akiyama et al., 2000; Lynch, 2013). As reviewed by several authors, microglial activation has been described in Alzheimer's disease (AD) (Fuller et al., 2009; Heneka and O'Banion, 2007; McGeer and McGeer, 2003), Parkinson's disease (PD) (Long-Smith et al., 2009; McGeer and McGeer, 2008; Ouchi et al., 2009) and indeed there is epidemiological evidence indicating that anti-inflammatory agents reduce the risk of AD (Launer, 2003; Rich et al., 1995; Vlad et al., 2008) and PD (Chen et al., 2005; Esposito et al., 2007).

It has become increasingly clear that to categorize microglia as resting or activated is simplistic, since the cells express a diverse array of receptors and therefore respond to an equally diverse array of ligands. Current evidence indicates that, like macrophages, microglia react differently to various stimuli. It is also simplistic to consider that microglia are a homogenous population of cells and emerging evidence indicates that there are probably regional differences. Microglia are unevenly distributed in the brain; in the mouse brain, microglial numbers are greater in grey matter than in white matter (Lawson et al., 1990), but the opposite has been reported in human brain (Mittelbronn et al., 2001). With respect to anatomical areas, overall microglial numbers are amongst the lowest in cerebellum of both mouse and human brain and highest in hippocampus of the mouse and medulla oblongata of the human (Lawson et al., 1990; Mittelbronn et al., 2001). Interestingly, phenotypic differences have been observed in unstimulated microglial cultures prepared from different brain regions, with higher mRNA expression of tumour necrosis factor alpha (TNF $\alpha)$, Fc gamma receptor and CD4 in microglia from hippocampus than other regions studied, including cortex and cerebellum (Ren et al., 1999). This, and other findings, raise the possibility that resting state microglia are a heterogeneous population with subgroups of microglia assigned specific 'house-keeping' functions, as so eloquently discussed in a recent review (Hanisch, 2013). The heterogeneity of microglia becomes more evident when cells shift from their resting state; for example, age-related changes in expression of different markers of microglial activation were found to be region-specific with the most profound changes in CD11b, CD68 and F4/80 observed in the cerebellum (Hart et al., 2012). 


\section{Microglial activation}

\subsection{Resting microglia}

The primary role of microglia under resting conditions is maintenance of homeostasis, neuroprotection and neurorepair, and repair, at least, is probably dependent on release of growth factors such as brain-derived neurotrophic factor (BDNF) and transforming growth factor (TGF) $\beta$ (Morgan et al., 2004). Time-lapse transcranial imaging of resting microglia showed that protrusion and retraction of processes is transient and occurs with high turnover. These processes make contact with astrocytes, neurons and blood vessels and sample the parenchyma every few hours. Tissue insult results in rapid recruitment of adjacent microglia and the appearance of spherical protrusions on their retracted processes, which is indicative of phagocytosis (Nimmerjahn et al., 2005). Interestingly, microglial interaction with presynaptic terminals and dendritic spines is dependent on neuronal activity (Wake et al., 2009).

\subsubsection{What factors contribute to the maintenance of microglia in a resting state?}

Resting microglia constitutively express surface receptors including complement receptors, Fc and $\mathrm{CD} 4$, and also $\mathrm{CD} 200$ and fractalkine receptors (CX3CR1) which are described as 'off signals' by Biber and colleagues in their review; these receptors engage with their respective ligands and help to maintain microglia in a quiescent state (Biber et al., 2007). Whereas CD200 is widely distributed, CD200 receptor expression is confined to cells of the myeloid lineage; consequently co-culturing of neurons with microglia decreases lipopolysaccharide (LPS)- or amyloid- $\beta$ (A $\beta$ )-induced microglial activation and this is dependent on interaction of CD200 with its receptor (Lyons et al., 2007a; Lyons et al., $2009 \mathrm{~b}$ ). The largely complementary expression of fractalkine on neurons and its receptor on microglia (Harrison et al., 1998) suggests an interaction similar to that described for CD200CD200R, and evidence to support this has been reported (Cardona et al., 2006; Lyons et al., 2009a). CD45 and signal regulatory protein (SIRP) $1 \alpha$, which are expressed predominantly on microglia, interact with neuronally expressed CD22 and CD47 respectively (Biber et al., 2007; Mott et al., 2004). These interactions appear to function as 'off' signals as do secreted CD22 and fractalkine (Biber et al., 2007), neurotrophins and anti-inflammatory cytokines such as interleukin (IL)-10 and IL-4 (Biber et al., 2007; Lyons et al., 2007b). These factors attenuate changes induced in microglia by stimuli that include interferon- $\gamma$ (IFN $\gamma$ ), LPS and $\mathrm{A} \beta$ (Clarke et al., 2008; Lyons et al., 2007b) and, interestingly, age-related decreases in expression of several of these 'off' signals have been reported (Lyons et al., 2009a; Moore et al., 2007; Nolan et al., 2005).

\subsection{The shift of microglia from their non-resting state and markers of activation}

Activated microglia typically upregulate expression of cell surface markers such as major histocompatibility complex (MHC) II and co-stimulatory molecules including CD80 and CD86 (Bhatia et al., 2006; Greenwald et al., 2005; Wolf et al., 2001), which enable microglia to interact with T cells and function as antigen presenting cells (APC). In addition, CD40 and CD11b, which are constitutively expressed on microglia, are upregulated upon activation (Nguyen and Benveniste, 2000; Qin et al., 2005; Streit et al., 1999; Tan et al., 2002); these contribute to activation and re-stimulation of T cells (Benveniste et al., 2004), production of inflammatory cytokines (Chen et al., 2006), cell motility, cell-mediated cytotoxicity and chemotaxis (Nagai et al., 2005; Solovjov et al., 2005; Weber et al., 1997), whereas upregulation of intercellular adhesion molecule (ICAM)-1 correlates with blood brain barrier permeability and leukocyte infiltration (Corti et al., 2004; Zameer and Hoffman, 2003). It has been repeatedly shown that increased expression of these markers of microglial activation is associated with impaired neuronal/synaptic function and therefore 
with deficits in different types of learning and memory and in the archetypal form of synaptic plasticity, long-term potentiation (LTP); for example, this relationship has been reported following treatment of animals with LPS or A $\beta$ and in aged animals (Clarke et al., 2008; Cowley et al., 2012; Lynch et al., 2007; Lynch, 2010).

\subsubsection{Microglia adopt different phenotypes in response to different stimuli}

It has been known for a few decades that macrophages adopt different activation states, identified by upregulation of specific markers, in response to diverse signals and this has been comprehensively reviewed (Gordon, 2003; Mosser, 2003). The activation states are broadly described as the classically-activated, or M1, phenotype and the alternativelyactivated, or M2, phenotype. Typically the Th1 cell-derived cytokine IFN $\gamma$ induces the M1 phenotype, which is identified by increased mRNA expression of TNF $\alpha$ and inducible nitric oxide synthase (iNOS). The term alternative activation (M2a phenotype) was first used to describe a macrophage which adopted a phenotype distinct from that induced by IFN $\gamma$ and LPS (Stein et al., 1992). These cells were not capable of producing nitric oxide (NO) and so were not cytotoxic and, although MHCII expression was increased, the cells were not efficient APC and prevented proliferation of T cells (Mosser, 2003). This phenotype is induced by the Th2 cell-derived cytokines, IL-4, IL-5 a nd IL-13 and is identified by increased mRNA expression of arginase 1, mannose receptor, chitinase 3-like 3 and found in inflammatory zone (FIZZ)-1. Two further M2 phenotypes have been described; the acquired deactivated (M2c) phenotype is induced by the immunosuppressive cytokines, IL-10 and TGF $\beta$, and is associated with upregulation of anti-inflammatory cytokines and downregulation of factors that contribute to APC function such as MHCII, whereas the immunoregulatory $\mathrm{M} 2 \mathrm{~b}$ phenotype is induced by a number of factors including immune complexes (Gordon, 2003). A recent comprehensive study revealed that, broadly, these phenotypes could be identified in cultured microglia (Chhor et al., 2013). Table 1 summarizes the characteristics of M1 and M2 phenotypes.

A significant issue relates to the nature of the stimuli that might trigger classical and alternative activation states in microglia in vivo since resident cells in the brain produce limited IFN $\gamma$ and IL-4. One possibility is that infiltrating cells are responsible for production of these cytokines and, consequently, for triggering polarization of microglia into classically- and alternatively-activated phenotypes. Increased expression of markers of M1 microglia have been correlated with evidence of infiltrating IFN $\gamma$-producing $\mathrm{T}$ cells and $\mathrm{NK}$ cells in the brain of aged animals and in transgenic mice that overexpress amyloid precursor protein (APP) and presenilin 1 (PS1; APP/PS1 mice), a commonly used animal model of AD (Kelly et al., 2013b; McManus et al., 2014; Minogue et al., 2014). A second possibility is that other polarizing stimuli substitute for IFN $\gamma$ and IL-4 in the brain. LPS induces many characteristics of the M1 phenotype and therefore endogenously-produced toll-like receptor (TLR)4 ligands may provide the activation signal in vivo.

It seems that acute activation of microglia, leading to the M1 activation state, is protective, at least in ischaemia, as recently reviewed (Cherry et al., 2014), with the primary aim of the cells being to eliminate or neutralize the stressor that initiated the event. When this is achieved, it is believed that the cells return to their resting state, perhaps having transiently adopted the M2 activation state, to ensure tissue repair and restoration of function as reviewed by others (Cherry et al., 2014; Colton and Wilcock, 2010). However, it is believed that chronic activation of microglia is damaging to tissue and the evidence suggests that this occurs with age and, to a significant extent, in neurodegenerative diseases as recently reviewed (Cherry et al., 2014). 
Table 1. Microglial phenotypes and characteristics

\begin{tabular}{|c|c|c|c|c|}
\hline \multicolumn{2}{|r|}{ Phenotype/Role } & Activating & Primary phenotypic & Cytokines produced \\
\hline M1 & $\begin{array}{ll}\text { - } & \text { Classical activation } \\
\text { - } & \text { Protection against } \\
& \text { insult }\end{array}$ & $\begin{array}{l}\text { IFN } \gamma, \text { LPS, } \\
\text { TNF } \alpha\end{array}$ & $\begin{array}{l}\text { iNOS, TNF } \alpha, \text { MHCII, } \\
\text { CD86 }\end{array}$ & $\begin{array}{l}\text { Inflammatory cytokines } \\
\text { e.g. IL-12, IL-1 } \beta \text {, IL-6, } \\
\text { IL-2 }\end{array}$ \\
\hline M2a & 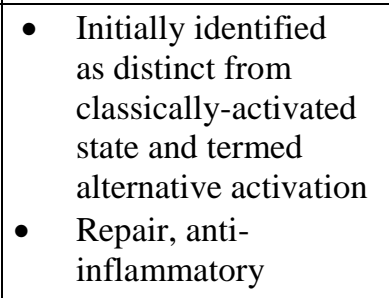 & IL-4, IL-13 & $\begin{array}{l}\text { Mannose receptor, } \\
\text { arginase } 1, \text { FIZZ-1, } \\
\text { chitinase } 3 \text {-like 3, } \\
\text { chemokines and } \\
\text { receptors including } \\
\text { CX3CR1, CCL2, } \\
\text { CCR2 }\end{array}$ & IL-10, IL-1ra, TGF $\beta$ \\
\hline M2b & $\begin{array}{l}\text { Modulatory/ } \\
\text { regulatory } \\
\text { phenotype }\end{array}$ & $\begin{array}{l}\text { Immune } \\
\text { complexes }\end{array}$ & $\begin{array}{l}\text { IL-10, cyclooxygenase } \\
\text { (COX)2, sphingosine } \\
\text { kinase, suppressor of } \\
\text { cytokine signaling } \\
\text { (SOCS)3 }\end{array}$ & $\begin{array}{l}\text { IL-1 } \beta \text {, IL-6, IL-10, } \\
\text { TNF } \alpha\end{array}$ \\
\hline M2c & $\begin{array}{l}\text { - } \\
\text { Acquired, deactivated } \\
\text { state } \\
\text { - Anti-inflammatory }\end{array}$ & IL-10, TGF $\beta$ & CD163 & IL-10, TGF $\beta$ \\
\hline
\end{tabular}

\subsection{Microglial activation is associated with decreased LTP}

The importance of microglial activation in modulating neuronal function, particularly hippocampal function, has been recognized for decades since the first observations that IL$1 \beta$ (and latterly other inflammatory cytokines), inhibit hippocampal-dependent learning, for example spatial learning (Oitzl et al., 1993 Gahtan and Overmier, 2001; Gibertini, 1998), and contextual fear conditioning (Maier and Watkins, 1995; Pugh et al., 1998; 1999; 2000). Indeed these reports post-date the recognition that IL- $1 \beta$ exerts an inhibitory effect on LTP in CA1 (Bellinger et al., 1993), CA3 (Katsuki et al., 1990) and dentate gyrus in vitro (Cunningham et al., 1996). These reports were followed by several others indicating similar inhibitory effects of IL-1 $\beta$ on LTP in vivo (Murray and Lynch, 1998), and the acknowledgement that the inhibitory effect of LPS and age on LTP may be a consequence of increased hippocampal expression of IL-1 $\beta$ (Murray and Lynch, 1998).

\subsubsection{What is the basis of the inverse correlation between microglial activation and the deficit in LTP?}

The most parsimonious explanation for the negative impact of A $\beta$, LPS and age on LTP is that activated microglia release inflammatory mediators, including pro-inflammatory cytokines such as IL-1 $\beta$, IL-6 and TNF $\alpha$, which have been known for many years to impair LTP in vivo and in vitro as reviewed previously (Lynch, 2010); the extent of the change in LTP varies with preparation (in vivo vs in vitro), concentration and cytokine, although in most cases, induction of LTP is spared. Additionally, potent activators of microglia e.g. IFN $\gamma$, which induces release of inflammatory cytokines from microglia, also inhibit LTP (Kelly et al., 2013a) and interestingly this effect is blocked by the anti-inflammatory cytokine, IL-4 (Maher et al., 2006).

The age-related increase in microglial activation, as indicated by expression of markers such as MHCII and CD68, appears to confer a susceptibility to inflammatory 
stimuli such that their effects on aged animals are more marked than on young animals. Specifically, an increase in production of inflammatory cytokines is reported to be coupled with deficits in hippocampal-dependent learning tasks (Barrientos et al., 2006; Chen et al., 2008) and enhanced microglial activation (Lynch et al., 2010). A $\beta$ also induces a greater negative effect on LTP in aged, compared with young, rats and this is associated with an age-related increase in the effect of $A \beta$ on IL-1 $\beta$ concentration in the hippocampus (Lynch et al., 2007).

\subsubsection{Is there a link between astrocytic activation and LTP?}

Microglial activation is often accompanied by that of astrocytes, for example in aged animals and APP/PS1 mice (Cowley et al., 2012; Gallagher et al., 2012; Gallagher et al., 2013; Kelly et al., 2013a) and astrocytes, like microglia, release inflammatory cytokines (Cowley et al., 2012). Therefore, while there is a particularly strong link between microglial activation and LTP, the potential impact of astrocytic activation on LTP cannot be ignored. Indeed the critical role of astrocytes in controlling extracellular concentrations of neurotransmitters such as glutamate and GABA, as well as purines, by regulated uptake and release has been well described (Halassa et al., 2007) and these factors impact on LTP. Additionally, astrocytes modulate microglial activation. One possibility is that this may derive from the fact that astrocytes can release GABA, which activates GABA receptors expressed by microglia (Lee et al., 2011). It is clear that astrocytes can also release inflammatory factors that trigger microglial activation and therefore contribute to the changes that occur as a consequence of chronic inflammation (Pascual et al., 2012; von Bernhardi and Ramirez, 2001). On the other hand, astrocytes secrete soluble factors including growth factors and anti-inflammatory cytokines (Eng et al., 2000) that decrease microglial activation. It has been shown that conditioned medium obtained from astrocytes decreased hydrogen peroxide $\left(\mathrm{H}_{2} \mathrm{O}_{2}\right)$-induced reactive oxygen species (ROS) production, increased expression and activity of the antioxidant enzyme, haemoxygenase-1, and decreased IFN $\gamma$-induced inducible iNOS expression in microglia (Min et al., 2006). Astrocytes also modulate microglial activation by virtue of the fact that they express CD200 (Cox et al., 2013); indeed incubation of microglia with CD200-bearing astrocytic membrane preparations attenuates the LPS-induced increase in mRNA expression of IL-1 $\beta$, TNF $\alpha$ and IL-6 and the LPS-induced release of TNF $\alpha$ and IL-6 (Cox et al., 2013).

\subsubsection{Loss of 'off signals' is associated with microglial activation and deficits in LTP}

The inverse relationship between microglial activation and synaptic plasticity has been linked with a decrease in expression of 'off' signals. For example, decreased expression of CD200, which occurs with age or following A $\beta$ treatment (Lyons et al., 2007a), is associated with a poorer ability of animals to sustain LTP, and slices prepared from mice lacking CD200 also exhibit a deficit in LTP (Costello et al., 2011). Interestingly, the deficit in LTP in aged animals is attenuated by CD200Fc (Cox et al., 2012), whereas both the agerelated and A $\beta$-induced decrease in LTP is at least partially reversed by IL-4 (Lyons et al., 2007b; Nolan et al., 2005), which increases hippocampal expression of CD200 (Lyons et al., 2009b). The age-related deficit in LTP and accompanying increase in microglial activation, are also associated with decreased hippocampal expression of fractalkine (Lyons et al., 2009a) and IL-10 (Moore et al., 2007). The relationship between neuroinflammation, particularly microglial activation, and impaired LTP, has been consolidated by the finding that strategies which attenuate microglial activation, including polyunsaturated fatty acids, statins or anti-inflammatory cytokines, also attenuate the loss of LTP (Adams et al., 1998); this is the case in a number of models in which LTP is decreased including in A $\beta$ - and LPStreated animals and in aged animals (Clarke et al., 2008; Clarke et al., 2007; Cowley et al., 
2012; Kelly et al., 2001; Kelly et al., 2011; Nolan et al., 2005). Figure 1 summarizes the factors that contribute to the age-related attenuation of LTP.

Figure 1. Proposed sequence leading to age-related decrease in LTP

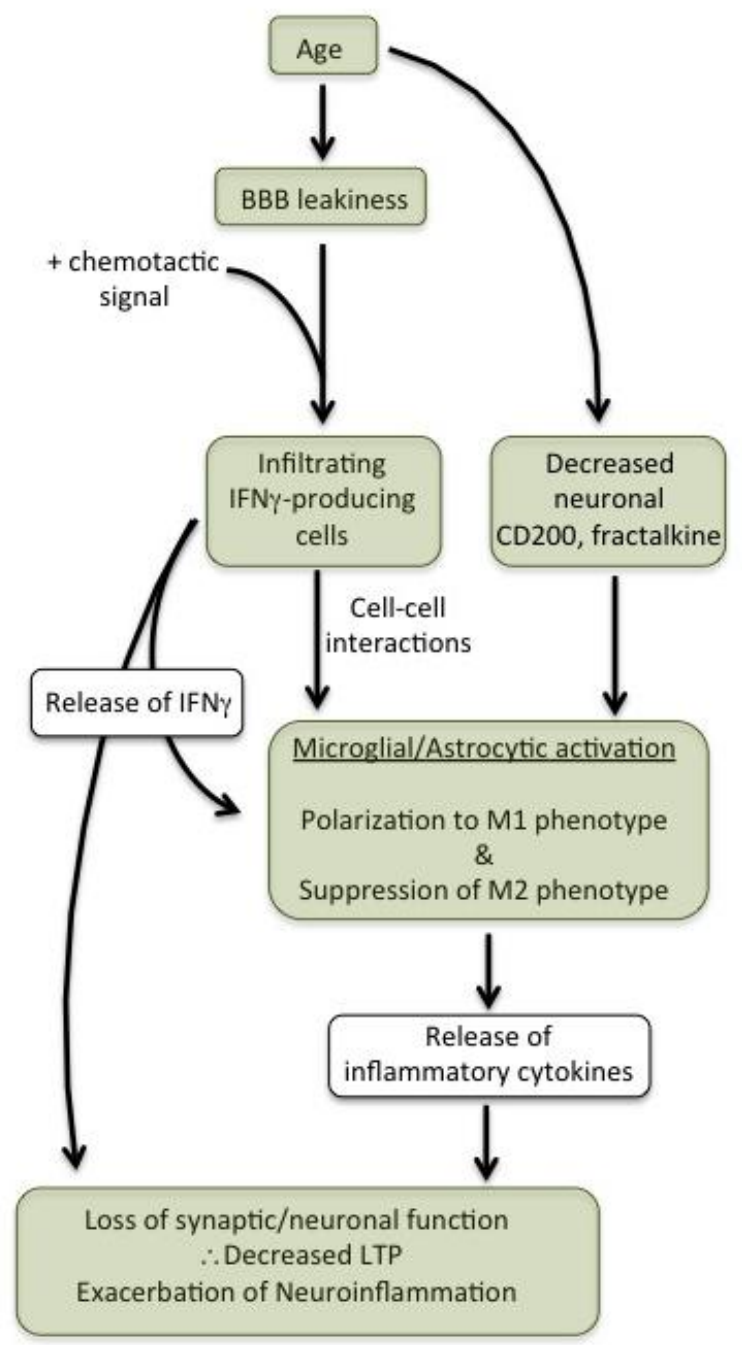

Age is associated with increased blood brain barrier permeability which, together with a chemotactic signal, increases infiltration of peripheral cells. These include NK and Th1 cells, which produce IFN $\gamma$, and this has a negative impact on LTP but also induces microglia, and probably astrocytes, to adopt the inflammatory M1 phenotype. These cells consequently increase production of inflammatory cytokines and reactive oxygen and nitrogen species which results in a loss of synaptic function and therefore LTP, while contributing to the existing neuroinflammation. In addition, age is associated with decreased expression of neuromodulatory molecules such as CD200 and fractalkine, which contribute to the maintenance of microglia in a quiescent state. This loss of control on microglia also permits increased production of inflammatory cytokines. It is proposed that a similar sequence of events occurs in models of Alzheimer's disease. 


\section{Microglial activation, $A \beta$ and LTP}

\subsection{A $\beta$ inhibits LTP}

The ability of $\mathrm{A} \beta$ to induce microglial activation (Combs et al., 2001; Lyons et al., $2007 \mathrm{~b}$ ) and increase the expression and release of IL-1 $\beta$ and TNF $\alpha$ from microglia (Lyons et al., 2012; McQuillan et al., 2010) is well-documented. This might suggest that inflammatory changes are A $\beta$-driven (Hensley, 2010), although this linear model is confounded by the finding that inflammatory cytokines increase APP processing (Blasko et al., 2000; Zhao et al., 2011).

Several authors have reported that different forms of $A \beta$ have the capacity to inhibit LTP in vivo and in vitro. One of the earliest papers reported that central administration of A $\beta$ inhibited LTP in area CA1 of the hippocampus (Cullen et al., 1997) and this observation was followed by several others which indicated that synthetic and naturally-occurring $\mathrm{A} \beta$ oligomers, including A $\beta$-derived diffusible ligands, inhibited LTP in all major afferent pathways in the hippocampus both in vivo and in vitro (Koffie et al., 2011; Ondrejcak et al., 2010; Walsh et al., 2002).

Although several groups have reported that acute A $\beta$ treatment inhibits LTP (Freir et al., 2001; Klyubin et al., 2004; Minogue et al., 2003; Walsh et al., 2002), fewer have examined the impact of chronic A $\beta$ perfusion. However, it has been shown that LTP was decreased in CA1 in slices prepared from rats treated with $\mathrm{A} \beta$ for 10 days (Itoh et al., 1999). Unpublished data from this laboratory have demonstrated that intracerebroventricular administration of $A \beta_{1-40}+A \beta_{1-42}$ for 1 month induced microglial activation and inhibited LTP, with others showing that spatial learning was inhibited by infusion of $A \beta_{1-42}$ for 23 (Yamada et al., 1999), 20 or 80 days (Nakamura et al., 2001), A $\beta_{1-40}$ for 14 days (Nitta et al., 1997) or $\mathrm{A} \beta_{1-40}+\mathrm{A} \beta_{1-42}$ for 1 or 2 months (Frautschy et al., 2001).

The $A \beta$-induced deficit in LTP in the dentate gyrus in vivo is associated with microglial activation and upregulation of inflammatory cytokines, with both the $A \beta$-induced microglial activation and decreased LTP being attenuated by IL-4, the polyunsaturated fatty acid, eicosapentaenoic acid and the HMG-CoA reductase inhibitor, atorvastatin (Clarke et al., 2007; Lynch et al., 2007; Lyons et al., 2007b; Minogue et al., 2007). Additionally, the $\mathrm{A} \beta$-induced inhibitory effect on LTP in CA1 in vitro was attenuated by pretreatment of slices with CD200Fc, which potently decreased the associated microglial activation (Lyons et al., 2012).

\subsection{Transgenic models of Alzheimer's disease and decreased LTP}

There is no doubt that microglial activation and the accompanying neuroinflammatory changes are associated with neuronal deficits that characterize AD, but it is not known whether these changes drive the pathology and loss of neuronal function, or are a consequence of the pathological processes. Similarly, increased expression of markers of microglial activation is likely to be a unifying theme in the brain of all animal models of AD (Li et al., 2013). One might predict that animal models would provide a clear indication of whether or not microglial activation drives the $A \beta$ accumulation or vice versa, however this has not been the case. A systematic examination of time-related changes in several parameters in $3 \mathrm{x}$ Tg mice revealed that increased activation of microglia and astrocytes occurred at 2 months of age. This was accompanied by increased expression of human APP and limited co-staining of APP and $A \beta$, but it occurred in advance of any evidence of intracellular or extracellular staining of $A \beta_{1-42}$ (Mastrangelo and Bowers, 2008). The authors suggested that these findings are consistent with a role for microglial activation in $A \beta$ deposition. In a separate study, it was suggested that microglial activation contributed to the neuronal loss in these animals (Janelsins et al., 2008). In contrast, albeit in a different model, 
APP/PS1 mice, microglial ablation appeared to have no effect on amyloidosis (Grathwohl et al., 2009). In the same model, we found that mRNA expression of IL-1 $\beta$, CD68 and CD11b, as well as the numbers of $\mathrm{CD} 11 \mathrm{~b}^{+} \mathrm{CD} 80^{+}$and $\mathrm{CD} 11 \mathrm{~b}^{+} \mathrm{MHCII}^{+}$cells, were increased in brain tissue from 7-9 month-old APP/PS1 mice, and that this was accompanied by evidence of A $\beta$ accumulation (Gallagher et al., 2013; O'Reilly and Lynch, 2012). In a separate study in 6 month-old APP/PS1 mice, we observed increases in concentrations of soluble and insoluble $\mathrm{A} \beta_{1-40}$ and $\mathrm{A} \beta_{1-42}$ but no increase in CD11b mRNA or in the number of $\mathrm{CD} 11 \mathrm{~b}^{+} \mathrm{CD} 80^{+}$or $\mathrm{CD} 11 \mathrm{~b}^{+} \mathrm{CD} 6^{+}$cells in the brain (McManus et al., 2014). These studies have not provided a clear indication that microglial activation contributes to deposition of $A \beta$, however several groups have reported that anti-inflammatory agents impact on $\mathrm{A} \beta$ accumulation, and also on the associated loss of synaptic plasticity (Li et al., 2013). A significant issue in the debate is the impact of an inflammatory microenvironment on phagocytic ability of microglia (and indeed macrophages). It has been reported that released inflammatory mediators and oxidative species from activated glia decrease phagocytic function (Hickman et al., 2008); others have similarly reported a negative impact of inflammatory mediators on microglial phagocytosis (Koenigsknecht and Landreth, 2004; Pan et al., 2011). In contrast antiinflammatory cytokines, and microglia which adopt the M2 activation state, appear to facilitate phagocytosis (Hjorth et al., 2013; Koenigsknecht-Talboo and Landreth, 2005; Mandrekar-Colucci et al., 2012).

The accumulating $A \beta$ burden, coupled with the associated microglial activation, appears to be irrevocably linked with a loss of synaptic plasticity in animals models of AD and, although it is not possible to identify the contribution of these factors separately, there is a great deal of evidence indicating that when the $A \beta$ burden is reduced, synaptic plasticity is restored, at least to some extent as reviewed previously ( $\mathrm{Li}$ et al., 2013; Marchetti and Marie, 2011). Among the first observations indicating that overexpression of APP, and the associated accumulation of A $\beta$, affected LTP was a study which reported that the deficit in vivo and in vitro was accompanied by an impairment in spatial working memory in 15-17 month-old $\mathrm{APP}_{695} \mathrm{SWE}$ mice (Chapman et al., 1999). Since that time, similar deficits in LTP and spatial learning have been described in other transgenic mouse models, including mice which overexpress APP and presenilin 1 (APP/PS1 mice) and $3 \mathrm{x}$ Tg mice which overexpress APP, PS1 and tau, as described in a number of comprehensive reviews (Braidy et al., 2012; Marchetti and Marie, 2011). While 6 month-old 3 x Tg mice exhibited a decrease in LTP in CA1, no change was observed in slices from 6 month-old APP/PS1 mice and it was suggested that the deficit was accounted for by an increase in intraneuronal $A \beta$ (Oddo et al., 2003). There is not complete agreement regarding the time at which changes in plasticity become apparent since there are reports of decreased LTP in APP/PS1 mice at 6 months (Marchetti and Marie, 2011) and even as early as 3 months of age (Trinchese et al., 2004).

It is striking that many potential therapies have the ability to reduce $A \beta$ accumulation and neuroinflammatory changes in animal models of $\mathrm{AD}$, and at least some of these have been shown to attenuate the loss of plasticity; these factors include immune therapies, antioxidants and modulators of glutamatergic, cholinergic and adrenergic receptor signalling and are comprehensively described in a recent review (Li et al., 2013). Many impact on microglial function with evidence that acetylcholine and noradrenaline attenuate microglial activation (Carnevale et al., 2007), an effect that is also attributed to activation of metabotropic glutamate receptor subtype 5 (Loane et al., 2009). Interestingly, A $\beta$ immunotherapy, in addition to decreasing the $A \beta$ burden, is capable of switching microglia into an activated phagocytic state (Koenigsknecht-Talboo et al., 2008; Wilcock et al., 2003; Wilcock et al., 2004). Anti-inflammatory strategies which inhibit microglial activation have also been shown to be useful in attenuating some of the changes in models of $\mathrm{AD}$, however 
although there is some evidence that long-term use of non-steroidal antiinflammatory treatment may reduce the risk of $\mathrm{AD}$, no beneficial effect in prospective clinical trials has been reported (Boche and Nicoll, 2008). There is, however, the caveat that if microglial activation is an event which triggers early changes, then treatment in established disease is unlikely to be especially advantageous.

Despite these promising pre-clinical leads, translation into clinical usefulness where deterioration of cognitive function is arrested or retarded, remains a challenge. Among the issues that need to be tackled is the ability of animal models to adequately reflect the full gamut of pathologies of $\mathrm{AD}$ and, in that context, identification of the triggers which precipitate the rapid loss of glial and neuronal function. Rational treatment strategies are likely to emanate from this, however the real key to successful treatment of AD is early diagnosis.

\section{Conclusions}

The negative impact of neuroinflammatory changes on neuronal function has been convincingly documented in the past decade or so and a key factor in driving neuroinflammation is glial activation, particularly activation of microglia. Although it is now accepted that microglia can adopt different activation states in response to diverse stimuli, in a manner somewhat analogous to macrophages, a great deal of work is necessary to gain a greater understanding of the functional phenotypes, the factors that control switching phenotypes in situ particularly in acute and chronic neuroinflammatory and/or neurodegenerative conditions, and the impact that switching might have on neuronal function.

\section{Acknowledgements}

The author gratefully acknowledges funding from Science Foundation Ireland, the Health Research Board Ireland and the Programme for Research in Third-Level Institutions (Ireland).

\section{References}

Adams, S., van der Laan, L. J., Vernon-Wilson, E., Renardel de Lavalette, C., Dopp, E. A., Dijkstra, C. D., Simmons, D. L., van den Berg, T. K., 1998. Signal-regulatory protein is selectively expressed by myeloid and neuronal cells. J Immunol 161, 18531859.

Akiyama, H., Barger, S., Barnum, S., Bradt, B., Bauer, J., Cole, G. M., Cooper, N. R., Eikelenboom, P., Emmerling, M., Fiebich, B. L., Finch, C. E., Frautschy, S., Griffin, W. S., Hampel, H., Hull, M., Landreth, G., Lue, L., Mrak, R., Mackenzie, I. R., McGeer, P. L., O'Banion, M. K., Pachter, J., Pasinetti, G., Plata-Salaman, C., Rogers, J., Rydel, R., Shen, Y., Streit, W., Strohmeyer, R., Tooyoma, I., Van Muiswinkel, F. L., Veerhuis, R., Walker, D., Webster, S., Wegrzyniak, B., Wenk, G., Wyss-Coray, T., 2000. Inflammation and Alzheimer's disease. Neurobiol Aging 21, 383-421.

Barrientos, R. M., Higgins, E. A., Biedenkapp, J. C., Sprunger, D. B., Wright-Hardesty, K. J., Watkins, L. R., Rudy, J. W., Maier, S. F., 2006. Peripheral infection and aging interact to impair hippocampal memory consolidation. Neurobiol Aging 27, 723-732.

Bellinger, F. P., Madamba, S., Siggins, G. R., 1993. Interleukin 1 beta inhibits synaptic strength and long-term potentiation in the rat CA1 hippocampus. Brain Res 628, 227234. 
Benveniste, E. N., Nguyen, V. T., Wesemann, D. R., 2004. Molecular regulation of CD40 gene expression in macrophages and microglia. Brain Behav Immun 18, 7-12.

Bhatia, S., Edidin, M., Almo, S. C., Nathenson, S. G., 2006. B7-1 and B7-2: similar costimulatory ligands with different biochemical, oligomeric and signaling properties. Immunol Lett 104, 70-75.

Biber, K., Neumann, H., Inoue, K., Boddeke, H. W., 2007. Neuronal 'On' and 'Off' signals control microglia. Trends Neurosci 30, 596-602.

Blasko, I., Veerhuis, R., Stampfer-Kountchev, M., Saurwein-Teissl, M., Eikelenboom, P., Grubeck-Loebenstein, B., 2000. Costimulatory effects of interferon-gamma and interleukin-1beta or tumor necrosis factor alpha on the synthesis of Abeta1-40 and Abeta1-42 by human astrocytes. Neurobiol Dis 7, 682-689.

Boche, D., Nicoll, J. A., 2008. The role of the immune system in clearance of Abeta from the brain. Brain Pathol 18, 267-278.

Braidy, N., Munoz, P., Palacios, A. G., Castellano-Gonzalez, G., Inestrosa, N. C., Chung, R. S., Sachdev, P., Guillemin, G. J., 2012. Recent rodent models for Alzheimer's disease: clinical implications and basic research. J Neural Transm 119, 173-195.

Cardona, A. E., Pioro, E. P., Sasse, M. E., Kostenko, V., Cardona, S. M., Dijkstra, I. M., Huang, D., Kidd, G., Dombrowski, S., Dutta, R., Lee, J. C., Cook, D. N., Jung, S., Lira, S. A., Littman, D. R., Ransohoff, R. M., 2006. Control of microglial neurotoxicity by the fractalkine receptor. Nat Neurosci 9, 917-924.

Carnevale, D., De Simone, R., Minghetti, L., 2007. Microglia-neuron interaction in inflammatory and degenerative diseases: role of cholinergic and noradrenergic systems. CNS Neurol Disord Drug Targets 6, 388-397.

Chapman, P. F., White, G. L., Jones, M. W., Cooper-Blacketer, D., Marshall, V. J., Irizarry, M., Younkin, L., Good, M. A., Bliss, T. V., Hyman, B. T., Younkin, S. G., Hsiao, K. K., 1999. Impaired synaptic plasticity and learning in aged amyloid precursor protein transgenic mice. Nat Neurosci 2, 271-276.

Chen, H., Jacobs, E., Schwarzschild, M. A., McCullough, M. L., Calle, E. E., Thun, M. J., Ascherio, A., 2005. Nonsteroidal antiinflammatory drug use and the risk for Parkinson's disease. Ann Neurol 58, 963-967.

Chen, J., Buchanan, J. B., Sparkman, N. L., Godbout, J. P., Freund, G. G., Johnson, R. W., 2008. Neuroinflammation and disruption in working memory in aged mice after acute stimulation of the peripheral innate immune system. Brain Behav Immun 22, 301311.

Chen, K., Huang, J., Gong, W., Zhang, L., Yu, P., Wang, J. M., 2006. CD40/CD40L dyad in the inflammatory and immune responses in the central nervous system. Cell Mol Immunol 3, 163-169.

Cherry, J. D., Olschowka, J. A., O'Banion, M. K., 2014. Neuroinflammation and M2 microglia: the good, the bad, and the inflamed. J Neuroinflammation 11, 98.

Chhor, V., Le Charpentier, T., Lebon, S., Ore, M. V., Celador, I. L., Josserand, J., Degos, V., Jacotot, E., Hagberg, H., Savman, K., Mallard, C., Gressens, P., Fleiss, B., 2013. Characterization of phenotype markers and neuronotoxic potential of polarised primary microglia in vitro. Brain Behav Immun.

Clarke, R. M., Lyons, A., O'Connell, F., Deighan, B. F., Barry, C. E., Anyakoha, N. G., Nicolaou, A., Lynch, M. A., 2008. A pivotal role for interleukin-4 in atorvastatinassociated neuroprotection in rat brain. J Biol Chem 283, 1808-1817.

Clarke, R. M., O'Connell, F., Lyons, A., Lynch, M. A., 2007. The HMG-CoA reductase inhibitor, atorvastatin, attenuates the effects of acute administration of amyloid-beta1-42 in the rat hippocampus in vivo. Neuropharmacology 52, 136-145.

Colton, C. A., Wilcock, D. M., 2010. Assessing activation states in microglia. CNS Neurol Disord Drug Targets 9, 174-191. 
Combs, C. K., Karlo, J. C., Kao, S. C., Landreth, G. E., 2001. beta-Amyloid stimulation of microglia and monocytes results in TNFalpha-dependent expression of inducible nitric oxide synthase and neuronal apoptosis. J Neurosci 21, 1179-1188.

Corti, R., Hutter, R., Badimon, J. J., Fuster, V., 2004. Evolving concepts in the triad of atherosclerosis, inflammation and thrombosis. J Thromb Thrombolysis 17, 35-44.

Costello, D. A., Lyons, A., Denieffe, S., Browne, T. C., Cox, F. F., Lynch, M. A., 2011. Long term potentiation is impaired in membrane glycoprotein CD200-deficient mice: a role for Toll-like receptor activation. J Biol Chem 286, 34722-34732.

Cowley, T. R., O'Sullivan, J., Blau, C., Deighan, B. F., Jones, R., Kerskens, C., Richardson, J. C., Virley, D., Upton, N., Lynch, M. A., 2012. Rosiglitazone attenuates the age-related changes in astrocytosis and the deficit in LTP. Neurobiol Aging 33, 162175.

Cox, F. F., Berezin, V., Bock, E., Lynch, M. A., 2013. The neural cell adhesion molecule-derived peptide, FGL, attenuates lipopolysaccharide-induced changes in glia in a CD200-dependent manner. Neuroscience 235, 141-148.

Cox, F. F., Carney, D., Miller, A. M., Lynch, M. A., 2012. CD200 fusion protein decreases microglial activation in the hippocampus of aged rats. Brain Behav Immun 26, 789-796.

Cullen, W. K., Suh, Y. H., Anwyl, R., Rowan, M. J., 1997. Block of LTP in rat hippocampus in vivo by beta-amyloid precursor protein fragments. Neuroreport 8, 32133217.

Cunningham, A. J., Murray, C. A., O'Neill, L. A., Lynch, M. A., O'Connor, J. J., 1996. Interleukin-1 beta (IL-1 beta) and tumour necrosis factor (TNF) inhibit long-term potentiation in the rat dentate gyrus in vitro. Neurosci Lett 203, 17-20.

Eng, L. F., Ghirnikar, R. S., Lee, Y. L., 2000. Glial fibrillary acidic protein: GFAPthirty-one years (1969-2000). Neurochem Res 25, 1439-1451.

Esposito, E., Di Matteo, V., Benigno, A., Pierucci, M., Crescimanno, G., Di Giovanni, G., 2007. Non-steroidal anti-inflammatory drugs in Parkinson's disease. Exp Neurol 205, 295-312.

Frautschy, S. A., Hu, W., Kim, P., Miller, S. A., Chu, T., Harris-White, M. E., Cole, G. M., 2001. Phenolic anti-inflammatory antioxidant reversal of Abeta-induced cognitive deficits and neuropathology. Neurobiol Aging 22, 993-1005.

Freir, D. B., Holscher, C., Herron, C. E., 2001. Blockade of long-term potentiation by beta-amyloid peptides in the CA1 region of the rat hippocampus in vivo. J Neurophysiol 85, 708-713.

Fuller, S., Steele, M., Munch, G., 2009. Activated astroglia during chronic inflammation in Alzheimer's disease-Do they neglect their neurosupportive roles? Mutat Res.

Gallagher, J. J., Finnegan, M. E., Grehan, B., Dobson, J., Collingwood, J. F., Lynch, M. A., 2012. Modest Amyloid Deposition is Associated with Iron Dysregulation, Microglial Activation, and Oxidative Stress. J Alzheimers Dis 28, 147-161.

Gallagher, J. J., Minogue, A. M., Lynch, M. A., 2013. Impaired Performance of Female APP/PS1 Mice in the Morris Water Maze Is Coupled with Increased Abeta Accumulation and Microglial Activation. Neurodegener Dis 11, 33-41.

Ginhoux, F., Greter, M., Leboeuf, M., Nandi, S., See, P., Gokhan, S., Mehler, M. F., Conway, S. J., Ng, L. G., Stanley, E. R., Samokhvalov, I. M., Merad, M., 2010. Fate mapping analysis reveals that adult microglia derive from primitive macrophages. Science 330, 841-845.

Gordon, S., 2003. Alternative activation of macrophages. Nat Rev Immunol 3, 23-35.

Grathwohl, S. A., Kalin, R. E., Bolmont, T., Prokop, S., Winkelmann, G., Kaeser, S. A., Odenthal, J., Radde, R., Eldh, T., Gandy, S., Aguzzi, A., Staufenbiel, M., Mathews, P. M., Wolburg, H., Heppner, F. L., Jucker, M., 2009. Formation and maintenance of 
Alzheimer's disease beta-amyloid plaques in the absence of microglia. Nat Neurosci 12 , 1361-1363.

Greenwald, R. J., Freeman, G. J., Sharpe, A. H., 2005. The B7 family revisited. Annu Rev Immunol 23, 515-548.

Halassa, M. M., Fellin, T., Haydon, P. G., 2007. The tripartite synapse: roles for gliotransmission in health and disease. Trends Mol Med 13, 54-63.

Hanisch, U. K., 2013. Functional diversity of microglia - how heterogeneous are they to begin with? Front Cell Neurosci 7, 65.

Harrison, J. K., Jiang, Y., Chen, S., Xia, Y., Maciejewski, D., McNamara, R. K., Streit, W. J., Salafranca, M. N., Adhikari, S., Thompson, D. A., Botti, P., Bacon, K. B., Feng, L., 1998. Role for neuronally derived fractalkine in mediating interactions between neurons and CX3CR1-expressing microglia. Proc Natl Acad Sci U S A 95, 1089610901.

Hart, A. D., Wyttenbach, A., Perry, V. H., Teeling, J. L., 2012. Age related changes in microglial phenotype vary between CNS regions: grey versus white matter differences. Brain Behav Immun 26, 754-765.

Heneka, M. T., O'Banion, M. K., 2007. Inflammatory processes in Alzheimer's disease. J Neuroimmunol 184, 69-91.

Hensley, K., 2010. Neuroinflammation in Alzheimer's disease: mechanisms, pathologic consequences, and potential for therapeutic manipulation. J Alzheimers Dis 21, 1-14.

Hickman, S. E., Allison, E. K., El Khoury, J., 2008. Microglial dysfunction and defective beta-amyloid clearance pathways in aging Alzheimer's disease mice. J Neurosci 28, 8354-8360.

Hjorth, E., Zhu, M., Toro, V. C., Vedin, I., Palmblad, J., Cederholm, T., Freund-Levi, Y., Faxen-Irving, G., Wahlund, L. O., Basun, H., Eriksdotter, M., Schultzberg, M., 2013. Omega-3 fatty acids enhance phagocytosis of Alzheimer's disease-related amyloid-beta42 by human microglia and decrease inflammatory markers. J Alzheimers Dis 35, 697-713.

Itoh, A., Akaike, T., Sokabe, M., Nitta, A., Iida, R., Olariu, A., Yamada, K., Nabeshima, T., 1999. Impairments of long-term potentiation in hippocampal slices of beta-amyloidinfused rats. Eur J Pharmacol 382, 167-175.

Janelsins, M. C., Mastrangelo, M. A., Park, K. M., Sudol, K. L., Narrow, W. C., Oddo, S., LaFerla, F. M., Callahan, L. M., Federoff, H. J., Bowers, W. J., 2008. Chronic neuron-specific tumor necrosis factor-alpha expression enhances the local inflammatory environment ultimately leading to neuronal death in 3xTg-AD mice. Am J Pathol 173, 1768-1782.

Katsuki, H., Nakai, S., Hirai, Y., Akaji, K., Kiso, Y., Satoh, M., 1990. Interleukin-1 beta inhibits long-term potentiation in the CA3 region of mouse hippocampal slices. Eur $\mathrm{J}$ Pharmacol 181, 323-326.

Kelly, A., Lynch, A., Vereker, E., Nolan, Y., Queenan, P., Whittaker, E., O'Neill, L. A., Lynch, M. A., 2001. The anti-inflammatory cytokine, interleukin (IL)-10, blocks the inhibitory effect of IL-1 beta on long term potentiation. A role for JNK. J Biol Chem 276, 45564-45572.

Kelly, L., Grehan, B., Chiesa, A. D., O'Mara, S. M., Downer, E., Sahyoun, G., Massey, K. A., Nicolaou, A., Lynch, M. A., 2011. The polyunsaturated fatty acids, EPA and DPA exert a protective effect in the hippocampus of the aged rat. Neurobiol Aging 32, 2318 e2311-2315.

Kelly, R. J., Minogue, A. M., Lyons, A., Jones, R. S., Browne, T. C., Costello, D. A., Denieffe, S., O'Sullivan, C., Connor, T. J., Lynch, M. A., 2013a. Glial Activation in A beta PP/PS1 Mice is Associated with Infiltration of IFN gamma-Producing Cells. Journal of Alzheimers Disease 37, 63-75. 
Kelly, R. J., Minogue, A. M., Lyons, A., Jones, R. S., Browne, T. C., Costello, D. A., Denieffe, S., O'Sullivan, C., Connor, T. J., Lynch, M. A., 2013b. Glial Activation in AbetaPP/PS1 Mice is Associated with Infiltration of IFNgamma-Producing Cells. J Alzheimers Dis.

Klyubin, I., Walsh, D. M., Cullen, W. K., Fadeeva, J. V., Anwyl, R., Selkoe, D. J., Rowan, M. J., 2004. Soluble Arctic amyloid beta protein inhibits hippocampal long-term potentiation in vivo. Eur J Neurosci 19, 2839-2846.

Koenigsknecht, J., Landreth, G., 2004. Microglial phagocytosis of fibrillar beta-amyloid through a beta1 integrin-dependent mechanism. J Neurosci 24, 9838-9846.

Koenigsknecht-Talboo, J., Landreth, G. E., 2005. Microglial phagocytosis induced by fibrillar beta-amyloid and IgGs are differentially regulated by proinflammatory cytokines. J Neurosci 25, 8240-8249.

Koenigsknecht-Talboo, J., Meyer-Luehmann, M., Parsadanian, M., Garcia-Alloza, M., Finn, M. B., Hyman, B. T., Bacskai, B. J., Holtzman, D. M., 2008. Rapid microglial response around amyloid pathology after systemic anti-Abeta antibody administration in PDAPP mice. J Neurosci 28, 14156-14164.

Koffie, R. M., Hyman, B. T., Spires-Jones, T. L., 2011. Alzheimer's disease: synapses gone cold. Mol Neurodegener 6, 63.

Launer, L., 2003. Nonsteroidal anti-inflammatory drug use and the risk for Alzheimer's disease: dissecting the epidemiological evidence. Drugs 63, 731-739.

Lawson, L. J., Perry, V. H., Dri, P., Gordon, S., 1990. Heterogeneity in the distribution and morphology of microglia in the normal adult mouse brain. Neuroscience 39, 151170.

Lee, M., Schwab, C., McGeer, P. L., 2011. Astrocytes are GABAergic cells that modulate microglial activity. Glia 59, 152-165.

Li, C., Ebrahimi, A., Schluesener, H., 2013. Drug pipeline in neurodegeneration based on transgenic mice models of Alzheimer's disease. Ageing Res Rev 12, 116-140.

Loane, D. J., Stoica, B. A., Pajoohesh-Ganji, A., Byrnes, K. R., Faden, A. I., 2009. Activation of metabotropic glutamate receptor 5 modulates microglial reactivity and neurotoxicity by inhibiting NADPH oxidase. J Biol Chem 284, 15629-15639.

Long-Smith, C. M., Sullivan, A. M., Nolan, Y. M., 2009. The influence of microglia on the pathogenesis of Parkinson's disease. Prog Neurobiol 89, 277-287.

Lynch, A. M., Loane, D. J., Minogue, A. M., Clarke, R. M., Kilroy, D., Nally, R. E., Roche, O. J., O'Connell, F., Lynch, M. A., 2007. Eicosapentaenoic acid confers neuroprotection in the amyloid-beta challenged aged hippocampus. Neurobiol Aging 28, 845-855.

Lynch, M. A., 2009. The multifaceted profile of activated microglia. Mol Neurobiol 40, 139-156.

Lynch, M. A., 2010. Age-related neuroinflammatory changes negatively impact on neuronal function. Front Aging Neurosci 1, 6.

Lynch, M. A., 2013. The impact of neuroimmune changes on development of amyloid pathology; relevance to Alzheimer's disease. Immunology.

Lyons, A., Downer, E. J., Costello, D. A., Murphy, N., Lynch, M. A., 2012. Dok2 mediates the CD200Fc attenuation of Abeta-induced changes in glia. $J$ Neuroinflammation 9, 107.

Lyons, A., Downer, E. J., Crotty, S., Nolan, Y. M., Mills, K. H., Lynch, M. A., 2007a. CD200 ligand receptor interaction modulates microglial activation in vivo and in vitro: a role for IL-4. J Neurosci 27, 8309-8313.

Lyons, A., Griffin, R. J., Costelloe, C. E., Clarke, R. M., Lynch, M. A., 2007b. IL-4 attenuates the neuroinflammation induced by amyloid-beta in vivo and in vitro. $\mathrm{J}$ Neurochem 101, 771-781. 
Lyons, A., Lynch, A. M., Downer, E. J., Hanley, R., O'Sullivan, J. B., Smith, A., Lynch, M. A., 2009a. Fractalkine-induced activation of the phosphatidylinositol-3 kinase pathway attentuates microglial activation in vivo and in vitro. J Neurochem 110, 1547 1556.

Lyons, A., McQuillan, K., Deighan, B. F., O'Reilly, J. A., Downer, E. J., Murphy, A. C., Watson, M., Piazza, A., O'Connell, F., Griffin, R., Mills, K. H., Lynch, M. A., 2009b. Decreased neuronal CD200 expression in IL-4-deficient mice results in increased neuroinflammation in response to lipopolysaccharide. Brain Behav Immun 23, 10201027.

Maher, F. O., Clarke, R. M., Kelly, A., Nally, R. E., Lynch, M. A., 2006. Interaction between interferon gamma and insulin-like growth factor-1 in hippocampus impacts on the ability of rats to sustain long-term potentiation. J Neurochem 96, 1560-1571.

Mandrekar-Colucci, S., Karlo, J. C., Landreth, G. E., 2012. Mechanisms Underlying the Rapid Peroxisome Proliferator-Activated Receptor-gamma-Mediated Amyloid Clearance and Reversal of Cognitive Deficits in a Murine Model of Alzheimer's Disease. J Neurosci 32, 10117-10128.

Marchetti, C., Marie, H., 2011. Hippocampal synaptic plasticity in Alzheimer's disease: what have we learned so far from transgenic models? Rev Neurosci 22, 373-402.

Mastrangelo, M. A., Bowers, W. J., 2008. Detailed immunohistochemical characterization of temporal and spatial progression of Alzheimer's disease-related pathologies in male triple-transgenic mice. BMC Neurosci 9, 81.

McGeer, E. G., McGeer, P. L., 2003. Inflammatory processes in Alzheimer's disease. Prog Neuropsychopharmacol Biol Psychiatry 27, 741-749.

McGeer, P. L., McGeer, E. G., 2008. Glial reactions in Parkinson's disease. Mov Disord 23, 474-483.

McManus, R. M., Higgins, S. C., Mills, K. H., Lynch, M. A., 2014. Respiratory infection promotes $\mathrm{T}$ cell infiltration and amyloid-beta deposition in APP/PS1 mice. Neurobiol Aging 35, 109-121.

McQuillan, K., Lynch, M. A., Mills, K. H., 2010. Activation of mixed glia by Abetaspecific Th1 and Th17 cells and its regulation by Th2 cells. Brain Behav Immun 24, 598-607.

Min, K. J., Yang, M. S., Kim, S. U., Jou, I., Joe, E. H., 2006. Astrocytes induce hemeoxygenase-1 expression in microglia: a feasible mechanism for preventing excessive brain inflammation. J Neurosci 26, 1880-1887.

Minogue, A. M., Jones, R. S., Kelly, R. J., McDonald, C. L., Connor, T. J., Lynch, M. A., 2014. Age-associated dysregulation of microglial activation is coupled with enhanced blood-brain barrier permeability and pathology in APP/PS1 mice. Neurobiol Aging 35, 1442-1452.

Minogue, A. M., Lynch, A. M., Loane, D. J., Herron, C. E., Lynch, M. A., 2007. Modulation of amyloid-beta-induced and age-associated changes in rat hippocampus by eicosapentaenoic acid. J Neurochem 103, 914-926.

Minogue, A. M., Schmid, A. W., Fogarty, M. P., Moore, A. C., Campbell, V. A., Herron, C. E., Lynch, M. A., 2003. Activation of the c-Jun N-terminal kinase signaling cascade mediates the effect of amyloid-beta on long term potentiation and cell death in hippocampus: a role for interleukin-1beta? J Biol Chem 278, 27971-27980.

Mittelbronn, M., Dietz, K., Schluesener, H. J., Meyermann, R., 2001. Local distribution of microglia in the normal adult human central nervous system differs by up to one order of magnitude. Acta Neuropathol 101, 249-255.

Moore, M., Piazza, A., Nolan, Y., Lynch, M. A., 2007. Treatment with dexamethasone and vitamin D3 attenuates neuroinflammatory age-related changes in rat hippocampus. Synapse 61, 851-861. 
Morgan, S. C., Taylor, D. L., Pocock, J. M., 2004. Microglia release activators of neuronal proliferation mediated by activation of mitogen-activated protein kinase, phosphatidylinositol-3-kinase/Akt and delta-Notch signalling cascades. J Neurochem 90, 89-101.

Mosser, D. M., 2003. The many faces of macrophage activation. J Leukoc Biol 73, 209212.

Mott, R. T., Ait-Ghezala, G., Town, T., Mori, T., Vendrame, M., Zeng, J., Ehrhart, J., Mullan, M., Tan, J., 2004. Neuronal expression of CD22: novel mechanism for inhibiting microglial proinflammatory cytokine production. Glia 46, 369-379.

Murray, C. A., Lynch, M. A., 1998. Evidence that increased hippocampal expression of the cytokine interleukin-1 beta is a common trigger for age- and stress-induced impairments in long-term potentiation. J Neurosci 18, 2974-2981.

Nagai, A., Mishima, S., Ishida, Y., Ishikura, H., Harada, T., Kobayashi, S., Kim, S. U., 2005. Immortalized human microglial cell line: phenotypic expression. J Neurosci Res 81, 342-348.

Nakamura, S., Murayama, N., Noshita, T., Annoura, H., Ohno, T., 2001. Progressive brain dysfunction following intracerebroventricular infusion of beta(1-42)-amyloid peptide. Brain Res 912, 128-136.

Nguyen, V. T., Benveniste, E. N., 2000. IL-4-activated STAT-6 inhibits IFN-gammainduced CD40 gene expression in macrophages/microglia. J Immunol 165, 6235-6243.

Nimmerjahn, A., Kirchhoff, F., Helmchen, F., 2005. Resting microglial cells are highly dynamic surveillants of brain parenchyma in vivo. Science 308, 1314-1318.

Nitta, A., Fukuta, T., Hasegawa, T., Nabeshima, T., 1997. Continuous infusion of betaamyloid protein into the rat cerebral ventricle induces learning impairment and neuronal and morphological degeneration. Jpn J Pharmacol 73, 51-57.

Nolan, Y., Maher, F. O., Martin, D. S., Clarke, R. M., Brady, M. T., Bolton, A. E., Mills, K. H., Lynch, M. A., 2005. Role of interleukin-4 in regulation of age-related inflammatory changes in the hippocampus. J Biol.Chem. 280, 9354-9362.

O'Reilly, J. A., Lynch, M., 2012. Rosiglitazone Improves Spatial Memory and Decreases Insoluble Abeta(1-42) in APP/PS1 Mice. J Neuroimmune Pharmacol 7, 140144.

Oddo, S., Caccamo, A., Shepherd, J. D., Murphy, M. P., Golde, T. E., Kayed, R., Metherate, R., Mattson, M. P., Akbari, Y., LaFerla, F. M., 2003. Triple-transgenic model of Alzheimer's disease with plaques and tangles: intracellular Abeta and synaptic dysfunction. Neuron 39, 409-421.

Ondrejcak, T., Klyubin, I., Hu, N. W., Barry, A. E., Cullen, W. K., Rowan, M. J., 2010. Alzheimer's disease amyloid beta-protein and synaptic function. Neuromolecular Med $12,13-26$.

Ouchi, Y., Yagi, S., Yokokura, M., Sakamoto, M., 2009. Neuroinflammation in the living brain of Parkinson's disease. Parkinsonism Relat Disord 15 Suppl 3, S200-204.

Pan, X. D., Zhu, Y. G., Lin, N., Zhang, J., Ye, Q. Y., Huang, H. P., Chen, X. C., 2011. Microglial phagocytosis induced by fibrillar beta-amyloid is attenuated by oligomeric beta-amyloid: implications for Alzheimer's disease. Mol Neurodegener 6, 45.

Pascual, O., Ben Achour, S., Rostaing, P., Triller, A., Bessis, A., 2012. Microglia activation triggers astrocyte-mediated modulation of excitatory neurotransmission. Proc Natl Acad Sci U S A 109, E197-205.

Qin, H., Wilson, C. A., Lee, S. J., Zhao, X., Benveniste, E. N., 2005. LPS induces CD40 gene expression through the activation of NF-kappaB and STAT-1alpha in macrophages and microglia. Blood 106, 3114-3122. 
Ren, L., Lubrich, B., Biber, K., Gebicke-Haerter, P. J., 1999. Differential expression of inflammatory mediators in rat microglia cultured from different brain regions. Brain Res Mol Brain Res 65, 198-205.

Rich, J. B., Rasmusson, D. X., Folstein, M. F., Carson, K. A., Kawas, C., Brandt, J., 1995. Nonsteroidal anti-inflammatory drugs in Alzheimer's disease. Neurology 45, 5155.

Solovjov, D. A., Pluskota, E., Plow, E. F., 2005. Distinct roles for the alpha and beta subunits in the functions of integrin alphaMbeta2. J Biol Chem 280, 1336-1345.

Stein, M., Keshav, S., Harris, N., Gordon, S., 1992. Interleukin 4 potently enhances murine macrophage mannose receptor activity: a marker of alternative immunologic macrophage activation. J Exp Med 176, 287-292.

Streit, W. J., Walter, S. A., Pennell, N. A., 1999. Reactive microgliosis. Prog Neurobiol 57, 563-581.

Tan, J., Town, T., Mori, T., Obregon, D., Wu, Y., DelleDonne, A., Rojiani, A., Crawford, F., Flavell, R. A., Mullan, M., 2002. CD40 is expressed and functional on neuronal cells. EMBO J 21, 643-652.

Trinchese, F., Liu, S., Battaglia, F., Walter, S., Mathews, P. M., Arancio, O., 2004. Progressive age-related development of Alzheimer-like pathology in APP/PS1 mice. Ann Neurol 55, 801-814.

Vlad, S. C., Miller, D. R., Kowall, N. W., Felson, D. T., 2008. Protective effects of NSAIDs on the development of Alzheimer disease. Neurology 70, 1672-1677.

von Bernhardi, R., Ramirez, G., 2001. Microglia-astrocyte interaction in Alzheimer's disease: friends or foes for the nervous system? Biol Res 34, 123-128.

Wake, H., Moorhouse, A. J., Jinno, S., Kohsaka, S., Nabekura, J., 2009. Resting microglia directly monitor the functional state of synapses in vivo and determine the fate of ischemic terminals. J Neurosci 29, 3974-3980.

Walsh, D. M., Klyubin, I., Fadeeva, J. V., Cullen, W. K., Anwyl, R., Wolfe, M. S., Rowan, M. J., Selkoe, D. J., 2002. Naturally secreted oligomers of amyloid beta protein potently inhibit hippocampal long-term potentiation in vivo. Nature 416, 535-539.

Weber, C., Erl, W., Weber, K. S., Weber, P. C., 1997. HMG-CoA reductase inhibitors decrease $\mathrm{CD} 11 \mathrm{~b}$ expression and $\mathrm{CD} 11 \mathrm{~b}$-dependent adhesion of monocytes to endothelium and reduce increased adhesiveness of monocytes isolated from patients with hypercholesterolemia. J Am Coll Cardiol 30, 1212-1217.

Wilcock, D. M., DiCarlo, G., Henderson, D., Jackson, J., Clarke, K., Ugen, K. E., Gordon, M. N., Morgan, D., 2003. Intracranially administered anti-Abeta antibodies reduce beta-amyloid deposition by mechanisms both independent of and associated with microglial activation. J Neurosci 23, 3745-3751.

Wilcock, D. M., Rojiani, A., Rosenthal, A., Subbarao, S., Freeman, M. J., Gordon, M. N., Morgan, D., 2004. Passive immunotherapy against Abeta in aged APP-transgenic mice reverses cognitive deficits and depletes parenchymal amyloid deposits in spite of increased vascular amyloid and microhemorrhage. J Neuroinflammation 1, 24.

Wolf, S. A., Gimsa, U., Bechmann, I., Nitsch, R., 2001. Differential expression of costimulatory molecules B7-1 and B7-2 on microglial cells induced by Th1 and Th2 cells in organotypic brain tissue. Glia 36, 414-420.

Yamada, K., Tanaka, T., Han, D., Senzaki, K., Kameyama, T., Nabeshima, T., 1999. Protective effects of idebenone and alpha-tocopherol on beta-amyloid-(1-42)-induced learning and memory deficits in rats: implication of oxidative stress in beta-amyloidinduced neurotoxicity in vivo. Eur J Neurosci 11, 83-90.

Zameer, A., Hoffman, S. A., 2003. Increased ICAM-1 and VCAM-1 expression in the brains of autoimmune mice. J Neuroimmunol 142, 67-74. 
Zhao, J., O'Connor, T., Vassar, R., 2011. The contribution of activated astrocytes to Abeta production: implications for Alzheimer's disease pathogenesis. $\mathbf{J}$ Neuroinflammation 8, 150. 